\title{
Vanished Twins and Misdiagnosed Sex: A Case Report with Implications in Prenatal Counseling Using Noninvasive Cell-Free DNA Screening
}

\author{
James F. Kelley, MD, JD, George Henning, MD, VMD, Anthony Ambrose, MD, and \\ Alan Adelman, $M D$
}

Cell-free DNA testing is a recently introduced method for screening pregnant women for fetal trisomy, which is associated with some common significant genetic diseases, as well as the sex of the fetus. The case described here demonstrates the connection between the ultrasound "vanishing twin" phenomenon and the misdiagnosis of prenatal sex using cell-free DNA testing. ( $\mathrm{J}$ Am Board Fam Med 2016;29:411-413.)

Keywords: Case Reports, Genetics, Obstetrics, Prenatal Care

In genetics evaluation aneuploidy is the determination that there is an abnormal number of chromosomes in an individual compared with the known wild type. ${ }^{1}$ Cell-free DNA testing, introduced in 2013 , is a new method of screening for fetal aneuploidy that functions by sequencing nonmaternal DNA drawn from maternal serum; it has mainly been used to test for trisomies 13, 18, and 21 in particular and can also screen for fetal sex and Rhesus (Rh) factor. ${ }^{2-6}$ Studies have demonstrated that the technique can also be used to test for fetal sex-linked diseases, such as hemophilia, Alport's syndrome, Hunter's syndromes, and Duchenne muscular dystrophy. ${ }^{7}$ A large, prospective, multicenter trial evaluated cell-free DNA testing for trisomies 13,18 , and 21 , and reported a negative predictive value of nearly $100 \%$ and a positive predictive value well above that provided by conventional testing, such as the

\footnotetext{
This article was externally peer reviewed.

Submitted 16 June 2015; revised 11 December 2015; accepted 14 December 2015.

From The Department of Family Medicine, Penn State Milton S. Hershey Medical Center, Hershey, PA.

Funding: none.

Conflict of interest: none declared.

Corresponding author: James F. Kelley, MD, JD, Department of Family and Community Medicine (JFK, GH, A. Adelman) and Department of Obstetrics and Gynecology, Division of Maternal Fetal Medicine (A. Ambrose), Penn State Milton S. Hershey Medical Center, 500 University Dr., Hershey, PA 17033 (E-mail: jkelley2@hmc.psu.edu).
}

quad screen. $^{2}$ In 2015 the American College of Gynecology released a committee opinion that stated that because of the recent availability of cell-free DNA testing and the lack of long-term data, they recommend conventional screening methods for most of the obstetric population. ${ }^{8}$ They further advised that "management decisions . . . should not be based on the results of cell-free DNA testing alone." "Vanishing twin" is a prenatal phenomenon in which a twin(s) fetus, found on a maternal ultrasound often during the first trimester, later involutes, leading to a singleton delivery. ${ }^{9}$ Our case demonstrates the impact a vanished twin can have on cell-free DNA testing.

\section{Case Report}

The patient is a 34-year-old woman (gravida 2, para 1001) who conceived naturally and presented to an emergency department at her sixth week of pregnancy because of vaginal bleeding. She received an ultrasound that demonstrated an intrauterine pregnancy. At 7 weeks and 4 days after her last menstrual period she received a follow-up ultrasound from the Department of Maternal Fetal Medicine. The scan found 2 gestational sacs, each containing a yolk sac. However, only 1 had a fetal pole with cardiac activity. The rest of the study was unremarkable. An additional ultrasound examination was ordered for 10 days later to determine whether 
the patient had a viable dichorionic twin pregnancy. The follow-up scan, performed at 9 weeks and 0 days, revealed a single intrauterine embryo with a heart rate of $170 \mathrm{bpm}$. The scan reported a second "amniotic/chorionic cavity," suggesting a "vanished twin." At 13 weeks and 1 day the patient received aneuploidy testing using noninvasive cellfree DNA testing. This technique uses DNA sequencing to detect fetal DNA present in the maternal blood. Sequencing demonstrated that the patient's fetus did not have a trisomy of chromosome 21,18 , or 13 , and that the sex chromosomes were XY. The patient subsequently underwent cesarean delivery of a normal-appearing female neonate at 39 weeks and 5/7 days. The pediatric genetics service was consulted to evaluate the sex of the child and to screen for possible androgen insensitivity syndrome. Ultrasound examination of the neonate demonstrated a normal prepubertal uterus. The infant's ovaries were not identified; however, according to the radiologist, they would not be expected to be visualized because the bladder was partially distended. Fluorescence in-situ hybridization of the neonate's DNA demonstrated a normal signal pattern for chromosomes 13, 18, and 21, and XX sex chromosomes were observed. The neonate's chromosome analysis was consistent with fluorescence in-situ hybridization (an XX karyotype), and the neonate was managed as a female during subsequent well-child visits. The XY chromosome discovered on prenatal testing was assumed to be from one of the "disappearing" twins noted previously.

\section{Discussion}

Our case demonstrates the need to understand that, while very accurate, cell-free DNA testing is ultimately a screening test, and a possibility of error can occur if it is relied on as a diagnostic instrument. This is especially true if there is a known disappearing twin(s). One study demonstrated that the vanishing twin phenomenon often occurs early, in the first trimester. ${ }^{9}$ The frequency of a vanishing twin among the general obstetric population was not been revealed in our literature review. Thurik and colleagues ${ }^{6}$ calculated the incidence of vanished twins through discordant $\mathrm{Rh}$ factor results, comparing $\mathrm{Rh}-$ fetuses with $\mathrm{RH}+$ cell-free DNA test results, and attributed the discordance to vanishing twin and determined that the phenomenon occurs in at least $0.23 \%$ of pregnancies. Our mother, having lost 2 fetuses, could reasonably be expected to have in her serum fetal DNA from the lost twins that would complicate noninvasive testing. Our case is similar to a 2014 case report in which cell-free DNA testing indicated a female fetus, and the mother subsequently gave birth to a healthy male. Those authors suspected, but could not prove, the presence of a vanishing twin. ${ }^{10}$ As noted above, Thurik and colleagues demonstrated that vanished twins could be responsible for discordance in $\mathrm{Rh}$ and sex classification using cell-free DNA. They found cases where "(b)oth the mother and the newborn are RhD-negative females, but the PCRs [polymerase chain reactions] in maternal plasma indicate the presence of an RHD-positive and Y-chromosome positive cell line. These results indicate cell-free DNA fragments in maternal plasma derived from a third cell line that is not representative for either the maternal genome or the genome of the vital fetus." A prospective study of the accuracy of cell-free DNA testing noted 2 cases of discordant cell-free DNA test results for trisomy 21 , which were associated with vanished twins. ${ }^{11}$ The authors concluded that "( $\mathrm{t}$ )he gender of the living and apparently healthy fetus was confirmed to be female and thus, the cffDNA that caused the increased $z$-score for trisomy 21 can clearly be assigned to a deceased male fetus." 11 When deciding to use noninvasive cellfree DNA testing in a case with a known vanished twin, physicians should consider the possibility of a false-positive result for trisomy 13, 18, or 21 and incorrect sex classification, as demonstrated by our case. In such cases it may be more prudent to consider chorionic villus testing or amniocentesis, which have $97.4 \%$ and $99 \%$ sensitivity, respectively. ${ }^{12}$ Clinicians ought to consider that cell-free DNA testing may also be responsible for a false-negative result. Hochstenbach and colleagues ${ }^{13}$ described 2 cases where cell-free DNA testing led to 2 false-negative results- 1 for trisomy 13 the other for trisomy 18 - which understandably led to significant anguish for the couples involved. In those cases ultrasound examination performed during the second trimester, however, did not reveal a vanished twin or empty sac, and the etiology of the false negative was unknown. Perhaps a vanished twin may have been discovered if the ultrasound occurred during the first trimester, before its involution. 


\section{References}

1. Griffiths AJF, Miller JH, Suzuki DT, Lewontin RC, Gelbart WM. Aneuploidy. In: An Introduction to Genetic Analysis. 7th Ed. New York: W.H. Freeman; 2000:589-635.

2. Bianchi D, Parker R, Wentworth J, et al; CARE Study Group. DNA sequencing versus standard prenatal aneuploidy screening. N Engl J Med 2014;370: 799-808.

3. Norton M, Jacobsson B, Swamy GK, et al. Cell-free DNA analysis for noninvasive examination of trisomy. N Engl J Med 2015;372:1589-97.

4. Porreco RP, Gariete TJ, Maurel K, et al. Noninvasive prenatal screening for fetal trisomies 21,18 , 13 and the common sex chromosome aneuplodies from maternal blood using massively parallel genomic sequencing of DNA. Am J Obst Gynecol 2014;211:e.1-12.

5. Futch T, Spinosa J, Bhatt S, de Feo E, Rava RP, Sehnert AJ. Initial clinical laboratory experience in noninvasive prenatal testing for fetal aneuploidy from maternal plasma DNA samples. Prenat Diagn 2013;33:569-74.

6. Thurik FF, Ait Soussan A, Bossers B, et al. Analysis of false-positive results of fetal RHD typing in a national screening program reveals vanishing twins as possible cause for discrepancy. Prenat Diagn 2015; 35:754-60.

7. Wright CF, Burton H. The use of cell-free fetal nucleic acids in maternal blood for non-invasive prenatal diagnosis. Hum Reprod Update 2009;15: $139-51$.

8. American College of Obstetricians and Gynecologists Committee on Genetics, Society for MaternalFetal Medicine. Committee opinion no. 640: Cell-free DNA screening for fetal aneuploidy. September 2015. Available from: http://www.acog.org/Resources-AndPublications/Committee-Opinions/Committee-onGenetics/Cell-free-DNA-Screening-for-FetalAneuploidy. Accessed December 9, 2015.

9. Sulakl LE, Dodson MG. The vanishing twin: pathologic confirmation of an ultrasonographic phenomenon. Obstet Gynecol 1986;68:811-5.

10. Vlková L, Hodosy J. Vanishing twin as a potential source of bias in non-invasive fetal sex determination: a case report. J Obstet Gynaecol Res 2014;40: $1128-31$.

11. Grömminger S, Yagmur E, Erkan S, et al. Fetal aneuploidy detection by cell-free DNA sequencing for multiple pregnancies and quality issues with vanishing twins. J Clin Med 2014;3:679-92.

12. Anderson CL, Brown CE. Fetal chromosome abnormalities: antenatal screening and diagnosis. Am Fam Physician 2009;79:117-23.

13. Hochestenbach R, Page-Christiaens GC. van Oppen AC, et al. Unexplained false negative results in noninvasive prenatal testing: two cases involving trisomies 13 and 18. Case Rep Genet 2015;2015: 926545 . 